\title{
COMPARATIVE STUDY BETWEEN THE DYNAMIC COMPRESSION PLATING (DCP) AND THE INTRAMEDULLARY INTERLOCKING NAILING IN DIAPHYSEAL FRACTURES OF THE HUMERUS IN ADULTS.
}

Naveen P.R ${ }^{1}$, Chaitanya P.R ${ }^{2}$

\section{HOW TO CITE THIS ARTICLE:}

Naveen PR, Chaitanya PR. "Comparative study between the dynamic compression plating (DCP) and the intramedullary interlocking nailing in diaphyseal fractures of the humerus in adults". Journal of Evolution of Medical and Dental Sciences 2013; Vol. 2, Issue 45, November 11; Page: 8704-8712.

ABSTRACT: AIMS: The aim of our study was to find the difference between the mean duration of union and functional outcome between the dynamic compression plating (DCP) and the intramedullary interlocking nailing in diaphyseal fractures of the humerus in adults. MATERIALS AND METHODS: From January 2007 to December 2008, 34 patients with diaphyseal fractures of the humerus were treated with compression plating using dynamic compression plate or with intramedullary interlocking nail. The time taken for radiological union in the two groups was compared. After satisfactory radiological union, the functional outcome was assessed by the "Disabilities of Hand, Shoulder and Elbow (DASH) Questionnaire". RESULTS: All fractures united and a marginal difference was noted in the time taken for union. The functional outcome was better in DCP group compared to interlocking nailing group which was statistically significant $(\mathrm{P}=0.010)$. The complication associated with interlocking group was more than the DCP group. CONCLUSION: We are of the opinion that when surgery is opted as a choice of treatment, both the modalities of treatment i.e. dynamic compression plating and interlocking nailing are good as far as union of the fracture is concerned, but considering the number of complications and functional outcome, we opine that dynamic compression plating offers better result than antegrade interlocking nailing with respect to pain and function of the shoulder joint.

INTRODUCTION: Fractures of the diaphysis of the humerus and its complications are a major cause of morbidity in trauma patients. Fractures of the humeral shaft account for $20 \%$ of the humeral fractures $^{1}$ and about 3-5 \% of all fractures ${ }^{2}$. Humeral fractures have a bimodal pattern in terms of age and sex of patients. The 1st peak is seen predominantly in young males in the age group 21-30 years mainly due to high energy trauma ${ }^{2}$. The 2 nd peak in seen in femal es of age 60-80 years caused primarily due to simple falls 2 .

Closed reduction is the mainstay of treatment of diaphyseal fractures of the humerus ${ }^{3}$ Operative treatment is required only if indicated ${ }^{2}$. Operative treatment commonly involves either plating or intramedullary nailing. The dynamic compression plate (DCP) is commonly used for plating and interlocking intramedullary nail is used for nailing.

Closed intramedullary nailing is widely accepted for the stabilization of femur and tibia. Nowadays it is also being applied to the fractures of the humerus. Plate fixation gives high rates of union, but requires extensive open operation with stripping of soft tissues from the bone ${ }^{4}$. It also provides less "secure "fixation, especially in osteoporotic bone and if crutch walking is required. Closed intramedullary nailing avoids all these problems.

Taking these points in mind, we undertook this study to compare these two modalities in the treatment of humerus fractures with respect to the mean duration for union \& the functional outcome. 


\section{MATERIALS AND METHODS:}

Source of Data: This study was conducted in the Department of Orthopaedic surgery at Fr Muller Medical College and Hospital, Mangalore between January 2007 to December 2008.

Method of Collection: Patients with diaphyseal fractures of the humerus with indications for surgical management were included in the study.

\section{Inclusion criteria}

1. All fractures of diaphysis of humerus indicated for surgical treatment.

2. Patients of age 18 years and above.

\section{Exclusion Criteria}

1. Fracture of upper and lower ends of humerus

2. Patients treated with other than dynamic compression plate or interlocking nail.

3. Patients with pre existing shoulder and elbow problems.

4. Pathological fractures.

5. Patients who were lost to follow up or died before the fracture union.

6. Patients with segmental fractures.

A thorough history was taken and clinical examination done after taking informed consent. The presence or absence of radial nerve injury was recorded. Roentgenogram of the arm with shoulder and elbow was taken in both antero-posterior and lateral views. Additional roentgenograms were taken if any other injury was suspected. The humeral shaft fracture was temporarily immobilized with a U-slab and arm pouch.

We used either dynamic compression plate or interlocking nail for 38 patients between January 2007 and December 2008 admitted at Fr Muller Medical College and Hospital, Mangalore for stabilization of fracture of the humeral diaphysis.

The 38 humeri of these 38 patients were prospectively randomised into two categories of dynamic compression plating or interlocking nailing by a computer generated list. Once the patients were randomized, pre-operative planning and investigations were done and the patients were posted for open reduction and internal fixation with DCP or interlocking nailing.

Anterolateral approach was used in patients with fractures of the upper and middle thirds of the shaft of the humerus. Posterior approach was used in patients with fractures of the lower thirds of the shaft. Only antegrade nailing was done in case of interlocking nailing group, none of the cases were treated by retrograde nailing. In the first group, $4.5 \mathrm{~mm}$ narrow DCP was used, and in second group standard intramedullary interlocking nail was used.

FOLLOW UP AND CRITERIA FOR EVALUATION: The patients were followed up every second week till radiological union was seen. At every follow up clinical examination was done to assess status of the surgical wound, pain, tenderness, range of motion of shoulder and elbow, stability of the fracture and clinical union. Roentgenograms were taken in AP and Lateral views to look for signs of radiological union.

In our study we concluded clinical union when the fracture site had become stable and pain free.

The union is confirmed radiologically when plain X-ray showed bone trabeculae or cortical bone crossing fracture site on at least three surfaces on orthogonal radiograms. 
The time taken for clinical and radiological union was noted. If there are no clinical and radiological signs of union by 16 weeks, the fracture was categorised as delayed union and if absence of fracture union after 32 weeks after injury was categorized as non union.

The functional outcome was measured by the "Disabilities of Arm, Shoulder and Hand" (DASH) Questionnaire at nine months or at full recovery which ever was earlier.

The DASH questionnaire has thirty questions the answers of which are graded from one to five points.

The functional score is calculated by the formula

DASH DISABILITY / SYMPTOM SCORE $\left.=\frac{\{(\text { sum of } \mathrm{n} \text { responses })}{\mathrm{N}}-1\right\} \times 25$

Where ' $\mathrm{N}$ ' is the number of responses. The best possible score is ' 0 ' and the worst possible score is ' 100 '. The functional outcome decreases as the score increases.

The result was then graded as Excellent, Good, Fair and Poor as follows 60

Excellent - 0 to 20 Points.

Good - 21 to 40 points.

Fair -41 to 60 points.

Poor - Greater than 60 points.

The time taken for radiological union and the functional outcome in both groups were then compared.

RESULTS: There were 38 patients in our study. Three patients were lost to follow up and 1 patient was excluded from the study as he was suffering from Alzheimer's disease and was not responding adequately to oral commands leaving us with 34 patients. Of the 34 fractures, 18 were fixed with dynamic compression plate and 16 were fixed by interlocking nail.

\begin{tabular}{|l|c|c|}
\hline \multicolumn{1}{|c|}{ Age } & DCP & Interlocking nailing \\
\hline Minimum & 22 & 23 \\
\hline Maximum & 65 & 84 \\
\hline Mean & 39.38 & 35.87 \\
\hline Standard deviation & 12.51 & 15.12 \\
\hline \multicolumn{2}{|c|}{ Table No. 1: Age of the Patients } \\
\hline
\end{tabular}

$\mathrm{t}=0.741, \mathrm{P}=0.464$

The age of the patients in the DCP group ranged from 22 to 65 years with a mean age of 39.38 years. The age in the interlocking group ranged from 23 to 84 years with a mean age of 35.87 years. By applying the Student' $t$ ' test, the t value came as 0.741 with $P$ value of $0.464(\mathrm{P}>0.05)$, which showed that there was no statistically significant difference in the age distribution of the two groups.

In DCP group anterolateral approach was used in 12 cases and posterior approach was used in 6 cases, among the interlocking group, only antegrade nailing was done. The average delay between injury and surgery was 5.5 days in the DCP group and 5.88 Days in the interlocking group. Mean delay was 5.69days.The average duration of follow up in our study was 11.44 months (range 6-17 months). 
ORIGINAL ARTICLE

\begin{tabular}{|c|c|c|c|}
\hline & DCP & Interlocking nailing & Total \\
\hline Healed within 4 months & $12(66.6 \%)$ & $14(87.5 \%)$ & $26(76.47 \%)$ \\
\hline Healed within 6 months & $5(27.77 \%)$ & $2(12.5 \%)$ & $7(20.58 \%)$ \\
\hline Non union & $1(5.55 \%)$ & $0 \%$ & $1(2.94 \%)$ \\
\hline Total & $18(100 \%)$ & $16(100 \%)$ & $34(100 \%)$ \\
\hline
\end{tabular}

Table No. 2: Distribution of Time taken for radiological healing of fractures

$\chi 2=2.3330, \mathrm{p}=0.312$

26 fractures healed within 4 months, 7 fractures healed within 6 months and 1 fracture failed to unite. So the average time taken for radiological healing was15 weeks and the range was 10-24 weeks. In the DCP group the average time was 17 weeks (range 12-24 weeks). In the interlocking nailing group the average was 13.6 weeks (range 10-20 weeks). So the healing rate was relatively faster in the interlocking group as compared to the DCP group. There was no statistically significant difference in the time taken for radiological union ( $\mathrm{P}$ value $=0.312$ )

\begin{tabular}{|c|c|c|c|}
\hline Group & Frequency & Mean score & Standard deviation \\
\hline DCP & 18 & 24.666 & 21.174 \\
\hline Interlocking nailing & 16 & 48.562 & 28.331 \\
\hline Total & 34 & 36.614 & 24.752 \\
\hline \multicolumn{2}{|r}{ Table No. 3: Statistical analysis of DASH score } \\
\hline
\end{tabular}

$\mathrm{Z}=2.758, \mathrm{P}=0.010 \mathrm{sig}$

DASH scores of 0-20 was taken as excellent, 21-40 was taken as good, 41-60 was taken as fair and above 61 was taken as poor.

The average DASH score of the whole series was 36.614 / 100 (Lower the score better the function). The average DASH score in the DCP group was 24.666 and in the interlocking nailing group it was 48.562 . As the $\mathrm{P}$ value is $0.010(<0.05)$, the results were statistically significant with respect to DASH score in both the groups.

Among 34 patients, 11 had excellent results, 9 had good, 8 had fair and 6 had poor results. Among the 11 patients with excellent results, 6 patients were treated by dynamic compression plating and 5 were treated by interlocking nailing. Among the 9 patients with good results, 5 patients were treated by dynamic compression plating and 4 were treated by interlocking nailing. Among the 8 patients with fair results, 5 were treated by dynamic compression plating and 3 were treated by interlocking nailing and lastly the 6 patients with poor results, 2 belong to the dynamic compression plating group, 4 patients belong to interlocking nailing group.

On statistical analysis, $\mathrm{P}$ value is $0.010(<0.05$, significant $)$ and also taking percentage into consideration, the dynamic compression plating group showed better results than the interlocking nailing group. 
ORIGINAL ARTICLE

\begin{tabular}{|l|c|c|c|}
\hline & DCP & Interlocking nailing & Total \\
\hline Iatrogenic palsy of radial nerve & $0 \%$ & $2(12.5 \%)$ & $2(5.88 \%)$ \\
\hline Non union & $1(5.55 \%)$ & $0 \%$ & $1(2.94 \%)$ \\
\hline Intraoperative communition/fracture & $0 \%$ & $2(12.5 \%)$ & $2(5.88 \%)$ \\
\hline Infection & $0 \%$ & $1(6.25 \%)$ & $1(2.94 \%)$ \\
\hline Severe impingement & $0 \%$ & $1(6.25 \%)$ & $1(2.94 \%)$ \\
\hline Adhesive capsulitis of shoulder & $1(5.55 \%)$ & $3(18.75 \%)$ & $4(11.76 \%)$ \\
\hline Secondary surgery & $1(5.55 \%)$ & $0 \%$ & $1(2.94 \%)$ \\
\hline \multicolumn{1}{|c|}{ Total } & $3(22.2 \%)$ & $9(56.6 \%)$ & $12(35.29 \%)$ \\
\hline
\end{tabular}

Table No. 4: Details of complications in both groups

Testing equality of proportion, $\mathrm{Z}=2.09$, $\mathrm{p}=0.036$, sig

In DCP group there were 3 complications (22.2\%) and in the interlocking nailing group there were 9 cases (56.6\%). Complications were more in interlocking nailing group, which was statistically significant $(\mathrm{p}=0.036)$.

In the DCP group there was no incidence of post operative radial nerve palsy. Whereas in interlocking group 2 of our patients had neuropraxia (12.5\%). As they were neuropraxias, they recovered fully.

The patient with implant breakage and non-union belonged to the DCP group and the cause was that the patient had started heavy weight lifting after 4 weeks leading to hypertrophic nonunion. He was advised bone grafting, which he refused. He had a poor result. There were no nonunions in the interlocking group.

One patient had suspected vascular injury with absent radial and ulnar pulse in interlocking group. A colour Doppler was done and found to be normal. He was kept under observation and recovered uneventfully. He had a C-3 type of fracture whose communited fragments were thought to be responsible for the spasm of the brachial artery. Patient had a fair result.

There was no infection in any patient of DCP group, whereas in interlocking nailing group 1 superficial infection developed which was derided immediately. The wound healed but the patient had a poor result.

Another patient required early removal of nail after fracture union as it was causing shoulder impingement. After removal, the abduction improved from 40 degrees to 60 degrees. Patient had a poor result.

Three patients developed adhesive capsulitis of the shoulder in the interlocking nailing group whereas there was only 1 patient in the DCP group and the cause in this patient being poor physiotherapy of the shoulder because of uncooperative patient. About 13 patients in the interlocking nailing group had some or the other residual pain in the shoulder.

In the DCP group, 1 patient had implant failure with screw back out due to improper technique in the early post operative period. Patient was reoperated and fracture was fixed with DCP again with bone-grafting. Fracture united. Patient had good result.

One patient in the interlocking group had fracture of the greater tuberosity of the humerus during antegrade nail insertion. However that fractures united and had no effect on the final outcome. Patient had an excellent result. 
One patient in the interlocking nailing group had communition at the fracture site during nail insertion. The fracture united but the patient had shoulder stiffness giving a poor result.

The interlocking nailing group had more complications $(56.60 \%)$ as compared to the DCP group (22.2\%). The test of significance, $\mathrm{Z}=2.09$ and $\mathrm{P}$ value $=0.036$, as the $\mathrm{P}$ value is less than 0.05 , the results were significant.

DISCUSSION: The indications for open reduction and internal fixation of acute fractures of the humeral shaft have been described as: fractures in patients with multiple injuries; open fractures; fractures associated with vascular or neural injuries or with lesions of the shoulder, elbow or forearm in the same limb; bilateral upper extremity injuries; fractures for which closed methods of treatment have failed and pathological fractures $5,6,7,8,9$. In several reported series the presence of associated multiple injuries was the most frequent indication for internal fixation of the humeral shaft $5,6,7,8,9$, in our study associated multiple injuries and road traffic accidents were most common indications.

In previous reports the incidence of non-union after plating has ranged from $2 \%$ to $4 \% 5,10$. In our DCP group the incidence of non-union is 5.5\%. Retrospective studies of locked intramedullary nail fixation quote incidences of non-union ranging from $0 \%$ to $8 \% 11,12,13,14$. In our series the incidence of non-union in the interlocking nail group is $0 \%$.

The incidence of radial nerve palsy with fracture shaft humerus varies from $6 \%$ to $15 \% 15,16,17$. In our series the incidence was $20.58 \%$. Out of the 7 cases, 5 cases recovered $(71.42 \%)$, which tallied with Seddon's and Pollock's series of $70 \%$ and $68 \%$ respectively.

In the DCP group the incidence of post operative radial nerve palsy is $2 \%$ to $5 \% 5,10$, but there were no such cases in our study. Whereas in interlocking group 2 of our patients had neuropraxia (12.5\%). As they were neuropraxias, they recovered fully. The incidence of post operative radial nerve palsy in various stu dies varies from $2.7 \%$ to $14.3 \% 18$.

The rate of intra operative communition during interlocking nail insertion with various studies varied from $7.7 \%$ to $10 \%{ }^{13,15}$. In our series there were $2(12.5 \%)$ intra operative communitions out of 16 patients treated with interlocking nailing. One occurred at fracture site due to hoop stress and the other at the greater tuberosity due to wrong entry portal.

Persistent pain after antegrade nailing is common 15,19,20. Habernek and Orthner ${ }^{21}$ in 1991 reported good results with Seidel's interlocking nail but later withdrew their support in 1998, as they had not assessed the shoulder functions of their patients properly. The cause of pain could be disruption of the rotator cuff in its avascular zone within $1 \mathrm{~cm}$ of its insertion to the greater tuberosity that may lead to poor healing22.

3 patients had developed adhesive capsulitis and 13 of our 16 patients in the interlocking nailing group reported some or the other shoulder pain. Our study confirms that antegrade insertion of nail can lead to problems with shoulder function and range of movement probably because of damage to the rotator cuff.

The union rates are comparable in both the groups with the results in excellent and good category are similar ( $\mathrm{p}$ value insignificant). There were more fair and poor results in the interlocking nailing group (27.70\% fair, $25.00 \%$ poor) compared to DCP group (18.75\%fair, $11.11 \%$ poor). The complications were more in the interlocking nailing group with most of them pertaining to poor 
shoulder function or pain and this difference in the complications was statistically significant $(\mathrm{p}=0.036)$.

Though interlocking intramedullary nailing is good for specific conditions like pathological fractures, segmental fractures or with associated lower limb fractures which require early weight bearing with crutch walking, we still consider DCP fixation is better than interlocking nailing in treating fractures of the diaphysis of the humerus.

Limitation of the study: We have not taken retrograde interlocking nailing into consideration.

CONCLUSION: We come to the conclusion that operative treatment of the humerus fractures should be done in patients with poly trauma and in patients with failed conservative treatment. Both the modalities of treatment i.e. dynamic compression plating and interlocking nailing are good as far as union of the fracture is concerned, but considering the functional outcome and rate of complications, we conclude that dynamic compression plating offers better result than interlocking nailing with respect to pain and function of the shoulder joint. We therefore conclude that in cases where both dynamic compression plating and interlocking nailing can be done, we would prefer to use dynamic compression plating, as the results are better than interlocking nailing.

\section{BIBLIOGRAPHY:}

1. Rose SH, Melton LJ, Morrey BF, Ilstrup DM, Riggs BL. Epidemiologic features of Humeral fractures. Clin Orthop 1982; 168; 24-30.

2. Buckholz RW, Heckman JD, Court-Brown CM, Koval KJ, Tornetta P, Wirth MA. Rockwood and Green's Fractures In Adults, Vol 1, 6th Edition, Lippincott Williams and Wilkins, 2006.

3. Gustilo RB, Kyle RF, Templeman D. Fractures and dislocations. 1st edition: Mosby publications; 1993.

4. David R, Jupiter, Jesse B. Internal Fixation of the Humerus with Locking Compression Plates .Journal of Techniques in shoulder and elbow surgery. Volume 4(4), December 2003, pp 169174.

5. Bell M.J, Beauchamp, Kellam JK and McMurtry. The Results of Plating Humeral Shaft Fractures in Patients with Multiple Injuries, the Sunny Brook Experience. JBJS Am 1985; Vol - 67; 293296.

6. Foster RJ, Dixon GL, Bach AW, Appleyard RW, Green TM. Internal Fixation of Fractures and Non-Unions of the Humeral Shaft. JBJS; vol 67-A; No 6; July 1985; 857-64.

7. McCormack RG, Brien D, Buckley RE, McKee, Powell J, Schemitsch EH. Fixation of fracture of shaft of humerus by dynamic compression plate or Intramedullary nail, J Bone Joint Surgery (Br) Toronto Canada, 2000; 82-B: 336-9.

8. Naiman PT, Schein AJ, Siffert RS. Use of ASIF compression plates in selected shaft fractures of the upper extremity. A preliminary report. Clin Orthop. 71:208-216. 1970

9. Pollock FH, Drake D, Bovill EG, et al. treatment of radial neuropathy associated with fracture shaft of humerus. JBJS (A) 1981; 63: 239-243

10. Heim D, Herkert F, Hess P, Regazzoni P. surgical treatment of humeral shaft fractures: the Basel experience. J Trauma: 1993: 35:226-232 
11. Crolla RMPH, deVries LS, Clevers CJ. Locked intramedullary nailing of humeral fractures. Injury 1993:24: 403-455.

12. Hems TE, Bhullar TP. Interlocking nailing of humeral shaft fractures: the Oxford experience 1991-1994. Injury 1996:27:485-489

13. lngman AM, Waters DA. Locked intramedullary..nailing of humeral shaft fractures. JBJS $\mathrm{Br}$ 1994:76-6: 23-24

14. Rommens PM., Verbrungen J, Bros PL. Retrograde locked nailing of humeral shaft fractures. J. Bone Joint Surg (Br) 1995; 77B: 84-89.

15. Garcia AJ, Maeck BH. Radial nerve injuries in the fractures of the shaft of the humerus. Am J Surg. 1960:99:625-627.

16. Kettlekamp DB, Alexander H. Clinical review of radial nerve injury. J trauma. 1967:7:424-432

17. Crates J. Whittle AP. Antegrade interlocking nailing of acute humeral shaft fractures. Clin Orthop 1998 May (350); 40-50.

18. Bain G, Sandow M. treatment of humeral shaft fractures with the Seidel intramedullary nail. JBJS Br. 1992; 74-b supp. I. 39-40

19. Brumback RJ, Bosse MJ, Poka A, Burgess AR. Intramedullary stabilization of humeral shaft fractures in patients with multiple trauma. JBJS AM. 1986; 68-A: 960-70

20. Habernek H, Orthner E. Locking nail for fractures of the humerus. JBJS-B. 1998.557.

21. Robinson CM, Bell KM, Court-Brown CM, McQueen MM. Locked nailing of humeral shaft fractures. JBJS-(A): 1992: 74-A: 558-562.

\section{Dynamic Compression Plating}

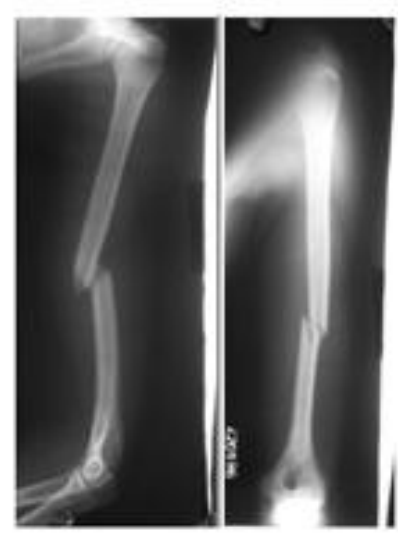

Pre-op



Post-op

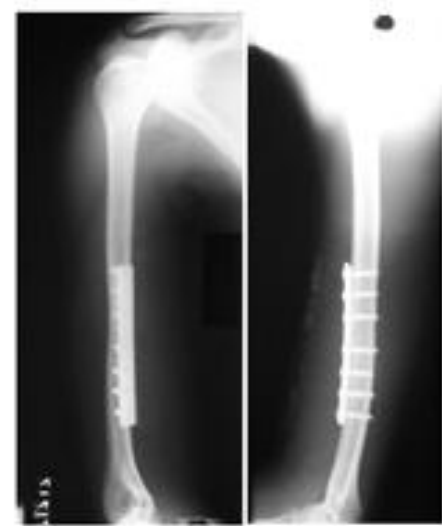

Union at 20 weeks 


\section{ORIGINAL ARTICLE}

\section{Interlocking Nailing}

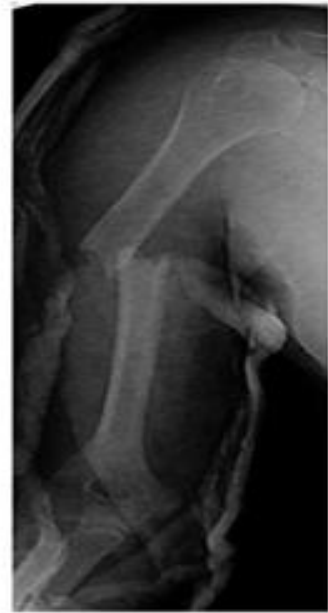

Pre-op



Union at 14 weeks

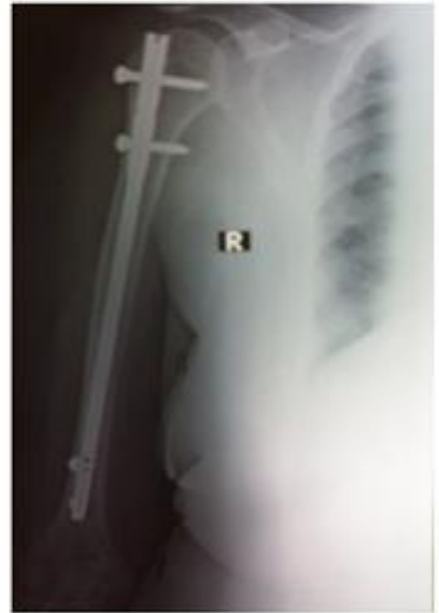

Union at 24 weeks

\section{AUTHORS:}

1. Naveen P.R.

2. Chai tanya P.R.

\section{PARTI CULARS OF CONTRIBUTORS:}

1. Assistant Professor, Department of Ortho paedics, S.I.M.S., Shivamogga.

2. Assistant Professor, Department of Ortho paedics, S.I.M.S., Shivamogga.
NAME ADDRESS EMAIL ID OF THE CORRESPONDING AUTHOR:

Dr. Naveen P.R., s/o, Mr. Rajappa P.L. \#32, "Shiva Krupa", $2^{\text {nd }}$ Cross, Keerthi Nagar, Shivamogga - 577201. Email -drnaveenpr@yahoo.com

Date of Submission: $27 / 10 / 2013$. Date of Peer Review: 28/10/2013. Date of Acceptance: 30/10/2013. Date of Publishing: 05/11/2013 